\title{
Acceptability of mandatory tuberculosis notification among private practitioners in Yogyakarta, Indonesia
}

\author{
Ari Kurniawati ${ }^{1}$, Retna S. Padmawati ${ }^{2}$ and Yodi Mahendradhata ${ }^{3 *}$
}

\begin{abstract}
Objective: Indonesia ranks second globally in the number of cases not reported to the National Tuberculosis Control Program, accounting for $11 \%$ of the total cases lost worldwide. In 2016, the Ministry of Health has issued Regulation Number 67 on tuberculosis control, which requires mandatory tuberculosis notification. We aimed to assess the prospective acceptability of mandatory tuberculosis notification among solo private practitioners and private primary care clinics in Yogyakarta.

Results: Our study highlighted critical issues which need to be addressed in ensuring acceptability of mandatory tuberculosis case notification. We found that that private practitioners do not notify tuberculosis cases due to a lack of policy knowledge. Mandatory tuberculosis notification and its potential penalties were also felt as burdensome by private practitioners. There were ethical concerns among the private practitioners in our study about patient's privacy and patients potentially lost to other healthcare facility. Private practitioners emphasized the need for intervention coherence and cooperation. We also observed pattern variations of these constructs across characteristics of private practitioners.
\end{abstract}

Keywords: Tuberculosis, Mandatory notification, Acceptability, Private practitioners, Indonesia

\section{Introduction}

Tuberculosis (TB) is globally one of the top ten causes of death and the leading cause from a single infectious agent [1]. In 2017, 6.4 million new cases of TB worldwide were formally reported to national TB control programs and then notified to the World Health Organization (WHO). As 10.0 million new cases have been estimated to occur in 2017, these reported 6.4 million cases reported only represented $64 \%$ of the estimated total new cases [1]. Thus, approximately 3.6 million cases are actually missed globally [1]. A combination of under-diagnosis and under-reporting of detected cases contribute to the gaps between the estimated number of new cases and the number notified [1].

\footnotetext{
*Correspondence: yodi_mahendradhata@yahoo.co.uk

${ }^{3}$ Department of Health Policy and Management, Faculty of Medicine,

Public Health and Nursing, Universitas Gadjah Mada, Yogyakarta, Indonesia

Full list of author information is available at the end of the article
}

Indonesia has the third highest TB burden in the world with 842,000 estimated cases occurring in 2017 [1]. Indonesia ranks also second globally in the number of cases not reported to the National TB Program, accounting for $11 \%$ of the total cases lost worldwide [1]. The Joint External Monitoring Mission 2017 reported that while around 7500 of the notified cases die, it is estimated that more than 100,000 deaths annually occur as unreported cases [2]. The majority of these missing cases are estimated to be in the private sector and unreported despite patients being able to access initial diagnosis and treatment $[2,3]$.

Evaluation of 98,000 Indonesian Medical Association members indicated that 7000 had participated in International Standard of Tuberculosis Care (ISTC) education programs by 2010, but only 1342 consistently reported TB case findings [4]. Mahendradhata et al. [5] found substandard management of TB cases among private practitioners in Indonesia. Stronger regulation is needed to ensure standard TB diagnosis, treatment and notification from 
the private sector [6]. The Ministry of Health has subsequently issued Regulation No. 67 of 2016 on tuberculosis control [7], which stipulated mandatory TB notification for private clinics and solo practices, with consequences of penalties for incompliance. Successful implementation of such policy arguably depends on its acceptability. The objective of this study is to explore the prospective acceptability of the TB mandatory notification policy, among solo private practitioners (PPs) and private primary care clinics in Yogyakarta municipality, Indonesia.

\section{Main text \\ Methods}

We conducted an explorative qualitative study to describe prospective acceptability of the mandatory notification policy of TB among solo PPs and private primary care clinics, in accordance with the Theoretical Framework of Acceptability (TFA) [8]. The qualitative approach has been chosen as it is most appropriate to answer questions about experience, meaning and perspective, most often from the standpoint of the participant [9]. These data are usually not amenable to counting or measuring [9].

The study is conducted in the setting of the Yogyakarta municipality, which is the capital of Yogyakarta Special Province, situated in southern part of the Java Island. The municipality covers an area of $32.5 \mathrm{~km}^{2}$ with a population of 409,487 [10]. Table 1 presents a summary of public and private health care facilities in Yogyakarta municipality [10]. There are currently 176 registered solo PPs in Yogyakarta; 55 of them are specialists while the rest are general practitioners (GPs). Additionally in Yogyakarta there are 17 private primary clinics that collaborate with the national health insurance agency. The National health insurance agency, which was established in 2014, has established TB case management guideline [11].

In line with the mandatory TB notification policy stipulated by the Minister of Health Regulation No. 67 of 2016, the Yogyakarta municipal government launched the Yogyakarta Regional Action Plan for TB Control 2017-2021 as stipulated in the Mayor Regulation No. 102 of 2017 [12]. This regulation calls for the increased involvement of private practitioners in $\mathrm{TB}$ case mandatory notification and intensification of TB case finding through training for private primary care centers and solo PPs.

We employed purposive sampling, rather than probabilistic sampling, for identifying and selecting individuals that are especially knowledgeable about or experienced with phenomenon of interest, i.e. mandatory TB notification [13]. We specifically used the maximum variation sampling strategy by identifying key dimensions of variations (e.g. characteristics of medical practice, medical qualification) and then finding cases that vary from each other (e.g. solo practitioners vs private clinic practitioners; general practitioners vs specialists) as much as possible [14]. This allowed us to document unique or diverse variations that have emerged in adapting to different conditions [13].

We initially recruited PPs based on the maximum variation sample constructed from the PPs register of the municipal health office, and cross-checked with the list from the medical association. We contacted the selected PPs and provided information on the study background, procedure and method before obtaining consent. Based on the information from PPs who were interviewed initially, we identify other potential informants to be recruited. As qualitative research approach place primary emphasis on information saturation, we continued to sample until no new substantive information is acquired, rather than following sample size estimation [13].

In-depth interviews were carried out from March to April 2018 by the first author (AK), who has been formally trained in qualitative research method, under supervision of a qualitative research expert. The indepth interviews were informed by an interview guide

Table 1 Public and private healthcare facilities in Yogyakarta Municipality [10]

\begin{tabular}{|c|c|c|c|}
\hline Public healthcare facilities & Number & Private healthcare facilities & Number \\
\hline Health Center without inpatient & 15 & General Hospital & 7 \\
\hline Health Center with inpatient & 3 & Specialized Hospital & 4 \\
\hline Satellite Health Center & 8 & Mother and Child Hospital & 5 \\
\hline Civil General Hospital & 2 & Health Clinic & 52 \\
\hline Military General Hospital & 1 & Beauty Clinic & 21 \\
\hline Military Clinic & 2 & Solo Private Medical practice & 176 \\
\hline \multirow[t]{5}{*}{ Police Clinic } & 2 & Solo Private Dental practice & 73 \\
\hline & & Midwifery practice & 13 \\
\hline & & Private Clinical Laboratory & 15 \\
\hline & & Pharmacy & 129 \\
\hline & & Traditional medicine practice & 113 \\
\hline
\end{tabular}


which were developed in consultation with qualitative research expert and tested beforehand with solo PPs practicing outside the Yogyakarta municipality. Questions in the interview guide focused on how PPs feel about participating in the TB mandatory notification policy; how much effort (time, effort, cost, thought) is felt to be needed to participate in $\mathrm{TB}$ mandatory notification policy; to what extent the $\mathrm{TB}$ mandatory notification policy has good conformity with the value system adopted by PPs; and how is PPs' understanding about the TB mandatory notification policy in advance and how the mandatory notification of TB cases works. The interview took approximately $1 \mathrm{~h}$ to complete. Each interview was audio recorded. Verbatim transcripts were developed based on the recoding and interview notes. We conducted thematic analysis guided by the relevant constructs of TFA [8]: affective attitudes, burdens, ethics, and coherence of interventions. To ensure trustworthiness, we performed triangulation, debriefing and member checking [15].

\section{Results}

We interviewed a total of 28 informants (Table 2) consisted of 9 solo PPs; 8 private clinic physicians and $11 \mathrm{~TB}$ program stakeholders (e.g. municipal health offices, primary health care centers, donor project technical officer).
Our interview data describe the prospective acceptability of mandatory TB case notification among solo PPs and private primary clinics, based on TFA constructs: affective attitude, burden, ethicality, and intervention coherence of mandatory TB notification. For each of these constructs, our results revealed general patterns as well as particular patterns across different characteristics of private practitioners.

\section{Affective attitudes}

This study found that PPs in Yogyakarta generally felt involved in the management of TB cases, but most did not report due to ignorance about the importance or lack of education concerning TB mandatory notification policy. This was also the case even for PPs who during the day served as civil servants and are in regular contact with the public primary health centers. The following excerpts from the interviews reflect this lack of policy knowledge.

"It's true that TB is also a government program, territorial actually..... But yes in this city I have never seen or heard or disseminated about this [mandatory notification policy], there is no term on how I should report if there is a case of TB"

(GP, Solo private practice)

Table 2 Characteristics of study informants

\begin{tabular}{|c|c|c|c|c|c|c|}
\hline \multicolumn{2}{|c|}{ Private practitioners } & \multicolumn{5}{|l|}{ Stakeholders } \\
\hline $\begin{array}{l}\text { Solo PP } \\
(n=9)\end{array}$ & $\begin{array}{l}\text { Private Clinic } \\
\text { Physician }(n=8)\end{array}$ & $\begin{array}{l}\text { City Health } \\
\text { Office }(n=2)\end{array}$ & $\begin{array}{l}\text { Provincial Health } \\
\text { Office }(n=2)\end{array}$ & $\begin{array}{l}\text { Donor project } \\
\text { Technical Officer } \\
(n=2)\end{array}$ & $\begin{array}{l}\text { Primary Health } \\
\text { Centers }(n=4)\end{array}$ & $\begin{array}{l}\text { Medical } \\
\text { Association } \\
(n=1)\end{array}$ \\
\hline
\end{tabular}

\begin{tabular}{|c|c|c|c|c|c|c|c|}
\hline \multicolumn{8}{|l|}{ Gender } \\
\hline Male & 3 & 2 & 0 & 1 & 1 & 1 & 0 \\
\hline Female & 6 & 6 & 2 & 1 & 1 & 3 & 1 \\
\hline \multicolumn{8}{|l|}{ Age } \\
\hline $25-34$ & 1 & 3 & 0 & 0 & 0 & 0 & 0 \\
\hline $35-44$ & 3 & 2 & 0 & 0 & 0 & 2 & 0 \\
\hline $45-54$ & 2 & 1 & 2 & 2 & 0 & 2 & \\
\hline $55-64$ & 2 & 1 & 0 & 0 & 1 & 0 & 1 \\
\hline$<65$ & 1 & 0 & 0 & 0 & 1 & 0 & 0 \\
\hline \multicolumn{8}{|c|}{ Academic background } \\
\hline Diploma & 0 & 0 & 0 & 0 & 0 & 1 & 0 \\
\hline Undergraduate & 0 & 0 & 1 & 0 & 0 & 1 & 0 \\
\hline Master degree & 0 & 0 & 0 & 2 & $2^{\mathrm{a}}$ & 0 & 0 \\
\hline Medical Doctor & 5 & 6 & 1 & 0 & $2^{a}$ & 2 & 0 \\
\hline Specialist & 4 & 2 & 0 & 0 & 0 & 0 & 1 \\
\hline \multicolumn{8}{|c|}{ Working experience (years) } \\
\hline$>5$ & 1 & 3 & 0 & 0 & 0 & 1 & 0 \\
\hline $5-10$ & 2 & 3 & 0 & 1 & 0 & 3 & 1 \\
\hline$>10$ & 6 & 2 & 2 & 1 & 2 & 0 & 0 \\
\hline
\end{tabular}

${ }^{a}$ Medical doctor with master degree 
"In my [practice] at home, I reported nothing....at the hospital there is already a system, there is a form for this."

(Specialist, Solo private practice)

"There was a TB training in 2013... in the end it was agreed that TB suspect should be sent to health centers to be managed. Unfortunately there has been no follow up [of this agreement]"

(GP, Solo private practice)

"Back then we knew that patients with coughs more than 2 weeks meet criteria for TB tracing, but...I don't know the reporting procedure. I have never followed any TB training or dissemination"

(GP, Private clinic)

\section{Burden}

This study found that mandatory notification of TB is generally quite burdensome for solo PPs both in terms of human resources and sanctions. Some argue it would not be a heavy burden, if there is a notification system and mechanisms that are easy and practical. The following excerpts from the interviews reflect this sense of burden and provide possible solutions.

"It's actually about human resources. When private practitioners cannot do it, it [reporting] can be delegated to medical record staff...If the practice is part of a clinic may be possible, but if for solo practice may be burdensome."

(GP, Private clinic)

"It is a big burden if the sanction is like that. ..... Maybe this rule must have requirements, explanations or disseminated first"

(GP, Private clinic)

"Reporting should be easy as there is not many cases. As long as there is a form and we do not have to make it ourselves"

(GP, Private clinic)

"...the forms should be provided ... softcopy or hardcopy...once a month...sent by email. Or perhaps with [mobile phone] applications would be more practical..."

(GP, Solo private practice)

\section{Ethicality}

The problem of ethicality encountered by some solo private practitioners involved physician-patient confidential relationships or relationships with other parties such as Primary Health Centers. There was also concerns over the possible risk of sharing of TB patient data (violation of privacy) for reporting purposes, or the risk of patients lost to other care providers. The following excerpts reflect a few ethical considerations which arose from the TB notification policy.

"Yes, so later if we report and then the patient knows....he is angry to us, it is also troublesome

(GP, Solo private practice)

"If the problem is about 'competing' for patients, well what's important is communication..."

(GP, Solo private practice)

"The concern that [their] patients are being taken away is understandable, certainly there is business interest in private [sector]"

(Officer, Municipal health office)

"Actually they will not just lose one patient [to health center], but many. One family may be 'lost', even the neighbors, when they hear from mouth to mouth that [private practitioner] cannot treat TB...."

(Provincial Technical Officer, International donor project)

\section{Intervention coherence}

The study also found that solo private practitioners and private primary clinics, as well as early stakeholders generally understood that mandatory TB notification is an important public health policy that contributes to improving case finding and is aimed to reduce drop-out rates for TB patients. They are ready to cooperate and contribute when there is a clear system and practical mechanism. The following excerpts reflect this need for intervention coherence and cooperation with the new TB notification policy.

"I do not think there's any additional obligation for this notification. Because after all, if not reported eventually can't be traced"

$$
\text { (GP of private primary clinic) }
$$

"There is no policy, for example in the city, that each of the Primary Health Center has to coordinate with the private sector in the area"

(Policy maker of Yogyakarta Health Office)

"For officially coordinating solo private practices and private clinics, frankly we do not dare yet because there is no mechanism and instruction yet 
from the [municipal] health office, we don't want to bypass them, we're ready if [the mechanism and instruction are] clear"

(Head, Health Center)

We observed some pattern variations of these constructs across characteristics of PPs (Table 3). Among GPs in solo private practices, the seniors notably expressed more burden and ethicality of mandatory TB case notification. Those who also served as civil servant during the day notably expressed less burden and ethicality of mandatory TB case notification. Among the specialists, burden and ethicality of mandatory TB case notification is more expressed by the pulmonologists.

\section{Discussion}

Our study highlighted critical issues which need to be addressed in ensuring acceptability of mandatory TB case notification. We found that that PPs may not notify TB cases due to a lack of policy knowledge. A study in India also highlighted that introduction of PPs to the notification program and their understanding about the importance and support for the notification program strongly determined their long-term involvement [16].

Mandatory TB notification and its potential penalties were also felt as burdensome by PPs in our study. In general, participation in any intervention involves time and cost, and often much cognitive effort, to foster individual confidence in engaging in a new intervention [8]. Thomas et al. [16] suggest that to facilitate effective TB notifications among solo PPs, user-friendly intervention strategies with different options can be used, especially smartphone media, such as direct telephone calls, SMS, or applications. Another study in India demonstrated that online case reporting platform improved accessibility to reporting for private providers, however remains time-consuming and require the support of an intermediary NGO to deal with the amount of required data [17].

There were ethical concerns among PPs in our study about patient's privacy and patients potentially lost to other healthcare facility. In line with our finding, Thomas et al. [16] also found that some PPs feared that the notifications would lead to privacy concerns or interfere with patient confidentiality. Chowdhury et al. further argued that TB mandatory notification breach the patients' right to confidentiality and that is particularly a matter of concern in a society where TB is widely stigmatized [18].

Additionally our findings emphasized the need for better intervention coherence. In line with Phalkey et al's [19] recommendations, the involvement of PPs requires periodic training, supportive supervision, and regular feedback to improve PPs' compliance with the mandatory TB notification policy. Uplekar [20] described five practical components required to facilitate a fully operational mandatory TB notification system to work optimally: policies and regulations, systems and reporting mechanisms, service provider orientation, feedback, and monitoring and evaluation. A study in South India also highlighted the need for a complete and coherent approach for enhancing notification, including improving healthcare providers' awareness regarding TB notifications requirement, establishing a single notification

Table 3 Summary of the prospective acceptability of mandatory TB notification among private practitioners in Yogyakarta, Indonesia

\begin{tabular}{|c|c|c|c|c|c|}
\hline Category & Sub category & $\begin{array}{l}\text { Affective attitude } \\
\text { of mandatory TB } \\
\text { notification }\end{array}$ & $\begin{array}{l}\text { Burden } \\
\text { of mandatory TB } \\
\text { notification }\end{array}$ & $\begin{array}{l}\text { Ethicality } \\
\text { of mandatory TB } \\
\text { notification }\end{array}$ & $\begin{array}{l}\text { Intervention coherence } \\
\text { of mandatory TB } \\
\text { notification }\end{array}$ \\
\hline \multirow{6}{*}{$\begin{array}{l}\text { General practitioner } \\
\text { (solo private practi- } \\
\text { tioner) }\end{array}$} & Senior & +- & +++ & +- & +++ \\
\hline & Junior & --- & --- & --- & +++ \\
\hline & High patient caseload & +- & +- & --- & +++ \\
\hline & Low patient caseload & --- & +- & --- & +++ \\
\hline & Government employees & --- & +- & +- & +++ \\
\hline & $\begin{array}{l}\text { Non-government } \\
\text { employees }\end{array}$ & +- & +- & +++ & +++ \\
\hline \multirow{4}{*}{$\begin{array}{l}\text { General practitioner (pri- } \\
\text { vate primary clinic) }\end{array}$} & Senior & +- & +- & --- & +++ \\
\hline & Junior & +- & +- & --- & +++ \\
\hline & High patient caseload & +- & +- & --- & +++ \\
\hline & Low patient caseload & --- & +- & --- & +++ \\
\hline \multirow{3}{*}{$\begin{array}{l}\text { Specialist (solo private } \\
\text { practitioner) }\end{array}$} & Pulmonologist & --- & +++ & +++ & +++ \\
\hline & Pediatrician & --- & --- & --- & +++ \\
\hline & Internist & +- & --- & --- & +++ \\
\hline
\end{tabular}


portal, digitally linking medical records and appointing one person to be responsible for notification [21]. There were notably some pattern variations of our findings across different characteristics of PPs. This underlines the need to customize the engagement approach to the characteristics of targeted PPs.

Therefore, our study highlighted important steps to be taken by key local actors, such as TB control program officers, who should pay particular attention to affective attitudes, burden, ethicality, and intervention coherence in order to ensure acceptability of mandatory TB notification policy. Enhancing affective attitudes and communications may alleviate the burdens and overcome ethical concerns related to mandatory TB notification. Coherence of interventions since the beginning of implementation is an especially important capital for the acceptability of mandatory TB notification at the next stages of implementation. There is a critical need to actively engage solo private practitioners in the mandatory $\mathrm{TB}$ notification policy. The Municipal Health Office and heads of the Primary Health Centers thus must strengthen their internal capacities to more systematically engage private practitioners and collaborate with key stakeholders.

Reflections from applying the Theoretical Framework of Acceptability [8] in our study may also contribute to further refine the framework. We found some TFA constructs to be overlapping especially between affective attitudes and intervention coherence, so some adjustments are recommended in the application of these constructs. We also recommend to further develop this theory by adding other external or environmental factors which influence the acceptability of new interventions.

\section{Limitations}

Our study have limitations which need to be considered to avoid overgeneralization. Firstly, we only conducted the study in Yogyakarta municipality, thus the findings should be interpreted prudently when considered in different settings. Secondly, not all of PPs we approached agreed to participate and there were limited participation among specialists. Thirdly, not all Heads of the Primary Health Centers could be interviewed. Thus, in order to minimize potential information gaps, we conducted additional interviews with key officers at the provincial health office who have played various key roles in the Public Private Mix TB program for more than 10 years.

\section{Abbreviations}

GP: general practitioners; ISTC: International Standards for Tuberculosis Care; PP: private practitioners; TB: tuberculosis; TFA: Theoretical Framework of Acceptability.

\section{Acknowledgements}

The authors would like to thank Yogyakarta Municipal Health Office and Yogyakarta Provincial Health Office. Especially to Alex Prasudi and Andajani Woerjandari for their support and inputs.

\section{Authors' contributions}

All authors contributed substantially to the conception or design of the work. AK collected and analyzed the data. RSP and YM contributed to interpretation of data for the work. AK drafted the manuscript. RSP and YM revised the manuscript critically for important intellectual content. All authors approved the version to be published and agreed to be accountable for all aspects of the work. All authors read and approved the final manuscript.

\section{Funding}

Not applicable.

\section{Availability of data and materials}

The datasets used and/or analysed during the current study are available from the corresponding author on reasonable request.

\section{Ethics approval and consent to participate}

The study protocol was reviewed and approved by the Medical and Health Research Ethics Committee of the Faculty of Medicine, Public Health and Nursing, Universitas Gadjah Mada, Yogyakarta, Indonesia. Written informed consents were obtained from all informants prior to interview.

\section{Consent for publication}

Not applicable.

\section{Competing interests}

The authors declare that they have no competing interests.

\section{Author details \\ ${ }^{1}$ Postgraduate Programme in Public Health, Faculty of Medicine, Public Health and Nursing, Universitas Gadjah Mada, Yogyakarta, Indonesia. ${ }^{2}$ Department of Health Behaviour, Environment, and Social Medicine, Faculty of Medicine, Public Health and Nursing, Universitas Gadjah Mada, Yogyakarta, Indonesia. ${ }^{3}$ Department of Health Policy and Management, Faculty of Medicine, Public Health and Nursing, Universitas Gadjah Mada, Yogyakarta, Indonesia.}

Received: 20 June 2019 Accepted: 21 August 2019

Published online: 27 August 2019

\section{References}

1. World Health Organization. Global tuberculosis report 2018. Geneva: WHO; 2018.

2. World Health Organization. The republic of Indonesia joint external monitoring mission tuberculosis 2017 Final Report. Jakarta:WHO; 2017.

3. Surya A, Setyaningsih B, Nasution HS, Parwati CG, Yuzwar YE, Osberg M, Hanson CL, Hymoff A, Mingkwan P, Makayova J, Gebhard A, Waworuntu W. Quality tuberculosis care in Indonesia: using patient pathway analysis to optimize Public-private collaboration. JID. 2017;216(S7):S724-32.

4. Ministry of Health Republic of Indonesia. National action plan of Indonesia TB public private mix 2011-2014. Jakarta: Ministry of Health Republic of Indonesia; 2011.

5. Mahendradhata Y, Lestari T, Probandari A, Indriarini LE, Burhan E, Mustikawati D, Utarini A. How do private general practitioners manage tuberculosis cases? A survey in eight cities in Indonesia. BMC Res Notes. 2015;8:564. https://doi.org/10.1186/s13104-015-1560-7.

6. Mahendradhata $Y$. The case for stronger regulation of private practitioners to control tuberculosis in low- and middle-income countries. BMC Res Notes. 2015. https://doi.org/10.1186/s13104-015-1586-x.

7. Ministry of Health Republic of Indonesia. Regulation of the Minister of Health Number 67 Year 2016 on Tuberculosis Control. Jakarta: Ministry of Health Republic of Indonesia; 2016.

8. Sekho M, Cartwright M, Francis JJ. Acceptability of healthcare interventions: an overview of reviews and development of a theoretical 
framework. BMC Health Serv Res. 2017;17:88. https://doi.org/10.1186/ s12913-017-2031-8.

9. Hammarberg K, Kirkman M, de Lacey S. Qualitative research methods: when to use them and how to judge them. Hum Reprod. 2016;31(3):498501. https://doi.org/10.1093/humrep/dev334.

10. Office Yogyakarta Municipal Health. Yogyakarta municipality health profile 2016. Yogyakarta: Yogyakarta Municipal Health Office; 2016.

11. Ministry of Health Republic of Indonesia. Technical guidelines for tuberculosis services for National Health Insurance Participant. Jakarta: Ministry of Health Republic of Indonesia; 2015.

12. Mayor of Yogyakarta. Regulation of mayor of yogyakarta number 102 year 2017 on regional action plan of tb control year 2017-2021. Yogyakarta: Mayor of Yogyakarta; 2017.

13. Palinkas LA, Horwitz SM, Green CA, Wisdom JP, Duan N, Hoagwood K. Purposeful sampling for qualitative data collection and analysis in mixed method Implementation Research. Adm Policy Ment Health. 2015;42:533-44. https://doi.org/10.1007/s10488-013-0528-y.

14. Suri H. Purposeful sampling in qualitative research synthesis. Qual Res J. 2011;11(2):63-75.

15. Shenton AK. Strategies for ensuring trustworthiness in qualitative research projects. Educ Inform. 2004;22(63-75):63.

16. Thomas BE, Velayutham B, Thiruvengadam K, Nair D, Barman SB, Jayabal L, Ovung S, Swaminathan S. Perceptions of private medical practitioners on Tuberculosis notification: a study from Chennai, South India. PLoS ONE. 2016;1 1(1):e0147579. https://doi.org/10.1371/journal.pone.0147579.
17. Ananthakrishnan R, Richardson MD, van den Hof S, Rangaswamy R, Thiagesan R, Auguesteen S, Kamp N. Successfully engaging private providers to improve diagnosis, notification, and treatment of tb and drug-resistant TB: the EQUIP public-private model in Chennai, India. Glob Health Sci Pract. 2019;7(1):41-53. https://doi.org/10.9745/GHSP-D-18-00318.

18. Chowdhury S, Phutke G, Patil S, Jain Y. The ethics of compulsory notification of tuberculosis. Indian J Med Ethics. 2019. https://doi.org/10.20529/ ijme.2019.013.

19. Phalkey RK, Butsch C, Belesova K, Kroll M, Kraas F. From habits of attrition to modes of inclusion: enhancing the role of private practitioners in routine disease surveillance. BMC Health Serv Res. 2017;17:599. https:// doi.org/10.1186/s12913-017-2476-9.

20. Uplekar M. Public-private mix for tuberculosis care and prevention. What progress? What prospects? Int J Tuberc Lung Dis. 2016;20(11):1424-9. https://doi.org/10.5588/ijtld.15.0536.

21. Siddaiah A, Ahmed MN, Kumar AMV, D'Souza G, Wilkinson E, Maung $T M$, Rodrigues R. Tuberculosis notification in a private tertiary care teaching hospital in South India: a mixed-methods study. BMJ Open. 2019;9(2):e023910. https://doi.org/10.1136/bmjopen-2018-023910.

\section{Publisher's Note}

Springer Nature remains neutral with regard to jurisdictional claims in published maps and institutional affiliations.
Ready to submit your research? Choose BMC and benefit from:

- fast, convenient online submission

- thorough peer review by experienced researchers in your field

- rapid publication on acceptance

- support for research data, including large and complex data types

- gold Open Access which fosters wider collaboration and increased citations

- maximum visibility for your research: over 100M website views per year

At BMC, research is always in progress.

Learn more biomedcentral.com/submissions 